\title{
A Scenario-Based Approach towards Open Collaboration for Policy Modelling
}

\author{
Melanie Bicking and Maria A. Wimmer \\ University of Koblenz-Landau, Universitaetsstr. 1, \\ 56070 Koblenz, Germany \\ \{bicking, wimmer\}@uni-koblenz.de
}

\begin{abstract}
In the context of current increasing variety, interconnectivity and alteration, many methods and tools for planning and decision-making such as time series analysis and trend extrapolation do not longer work out. Along the demands for good governance and open government, policy-makers need concise, reliable and up-to-date information to manage society's problems and affairs in an efficient and effective way. Likewise, stakeholders affected by a particular policy demand transparency, accountability and trustworthiness in political decision-making. Along the increasing digitisation of the Information Society, citizens are more and more requesting direct involvement in policymaking. The implementation of good governance principles as already defined a decade ago by OECD or the European Commission become predominant in societal evolution. In this contribution, a novel approach to policy development through collaborative scenario building via online means and formal modelling and simulation of policy is introduced. The approach adds value to current policy discussions by facilitating the understanding and assessment of specific policy issues, letting stakeholders express their views and concerns on a policy via collaborative scenarios and e-participation tools, and providing means to better understand consequences of policy choices.
\end{abstract}

Keywords: Scenario building, Policy development, Open collaboration, Stakeholder involvement.

\section{The ICT Demand for Governance and Policy Modelling}

Today's global challenges are interconnected, dynamic and complex in nature thereby having strong impact on the wellbeing of societies and economies. Dealing with complexity has become a key success factor for good governance in the 21 st century. To ensure sustainable wellbeing of societies and economies, policy makers must be able to cope with unwanted side effects from environmental changes and social dynamics.

Besides, disenchantment with politics and political parties characterise the current crisis of Europe's representative democracy (see latest turnout results at the European election $^{1}$, the voter turnout has kept falling about $2.37 \%$ from 2004 to 2009).

\footnotetext{
${ }^{1}$ See Results of the 2009 European Elections, http://www.elections2009-results.eu/en/turnout_en.html (last access 2011/06/11)
} 
Democracy has failed to secure greater political accountability. Vertical accountability, i.e. the obligation of political decision-makers to explain and to account their decisions towards their voters, comes to the fore ${ }^{2}$. In the course of these developments, governments all over the world place special emphasis on the concepts of Open Government and Good Governance.

The EC identified modelling, simulation and visualisation as path-breaking ICTs for Governance and Policy Modelling to trigger and shape significant changes in the way future societies will function ${ }^{3}$. However, results from the state of play analysis of the CROSSROAD project evidence that existing tools are far from being widespread; and the related research fields are still fragmented ${ }^{4}$.

The OCOPOMO ${ }^{5}$ project is one out of seven projects funded by the European Commission (EC) in the 7th Framework Programme in the field of ICT for governance and policy modelling. OCOPOMO integrates collaborative scenario building with agent-based modelling and simulation in order to empower and engage different types of societal groups and communities, to enable them to utilise eparticipation platforms and to allow governments to incorporate stakeholders' inputs in policy developments of two pilot cases. OCOPOMO encompasses three complementary research fields, which have traditionally been quite separated: (i) OCOPOMO relates to scenario building that allows stakeholders to conduct simple "what-if" and "if-then" exercises to inform modelling and simulation via narrative texts that stakeholders are usually familiar with. (ii) OCOPOMO refers to eparticipation to allow for open collaboration and online stakeholder involvement in order to facilitate compliance with the concept of Open Government and the principles for Good Governance. (iii) The combination of scenario building and stakeholder involvement through online means serves the common goal of improving public decision-making to handle complexity, to make policy-making and governance more effective and more intelligent, and to accelerate the learning path embedded in the policy cycle. With it, OCOPOMO contributes to the realisation of Open Government and the Good Governance principles.

In this paper, we present the OCOPOMO approach to address policy modelling through collaborative scenario building via online means thereby informing the model, on which the simulation will run. Section 2 introduces the concept of Open Government and the Good Governance principles of the EC, which ground the selection of scenario building for OCOPOMO explained in section 3 and lay the foundation for the OCOPOMO collaborative scenario approach outlined in section 4 . It also founds the evidence base for developing the use case related policy models

\footnotetext{
${ }^{2}$ Impact Assessment of European Commission Policies: Achievements And Prospects, EEAC Working Group Governance, online http: / / www . eeac-net.org/download/EEAC\%20WG\%20Gov_ IA 20statement_final_18-5-06.pdf (last access 2011/06/11).

${ }^{3}$ FP7 ICT Work Programme 2009-2010. European Commission, online http://ec.europa.eu/information_society/newsroom/cf/itemdetail .cfm?item_id=4535 (last access 2011/06/11).

${ }^{4}$ See Deliverable 1.2 - State of the Art Analysis of CROSSROAD, Crossroad consortium, online: http://crossroad. epu.ntua.gr/files/2010/04/CROSSROAD-D1. 2-State-of-the-Art-Analysis-v1.00.pdf (last access 2011/06/11)

5 OCOPOMO - Open Collaboration in Policy Development, see www . ocopomo . eu
} 
introduced with a use case example in section 5. Section 6 concludes with some remarks on future work. A more detailed introduction to the project, its objectives and the overall approach is available in [26], [27] and at the project website ${ }^{1}$.

\section{Open Government and Good Governance}

Open government aims to help governments to be more accessible and more responsive to their demands and needs. Open government is an essential ingredient for democratic governance, social stability and economic development. The principles of good governance stand for the basis upon which to build open government.

The concept of Good Governance describes ,the principles, approaches and guidelines for good governance and public administration to promote interaction and formation of political will with regard to societal and technological changes" [6].

The European Commission (EC) set up the following five principles for Good Governance $^{6}$ (see also [11] and [20]):

- Openness: Ensure transparent process of decision-making and implementation.

- Participation: Degree to which affected parties are involved in the policymaking life-cycle ${ }^{7}$.

- Coherence: Consideration of collateral effects on stakeholders caused by the policy.

- Effectiveness: Efficient delivery of quality outcomes. Policies have to be effective and established at the right time grounded on clear goals.

- Accountability: Roles and responsibilities should be clearly formulated and communicated.

Open Government aims to overcome the long-lasting culture of politics of secrecy where decisions were made without democracy and refers to public's right to know (cf. [16], [1]). A key principle of Open Government is Freedom of information (FOI) legislation that guarantees access to data held by the State. Many countries around the world have established FOI acts with the intention of establishing a system of transparency, public participation and collaboration [2]. The OECD argues three principles of Open Government [17]:

- Accountability: it is possible to identify and hold public officials to account for their actions;

- Transparency: reliable, relevant and timely information about the activities of government is available to the public;

- Openness: governments listen to citizens and businesses and take their suggestions into account when designing and implementing public policies.

Information and Communication Technology (ICT) has aided to disclose and disseminate information [21] and to contribute to implement Open Government.

\footnotetext{
${ }^{6}$ European Governance - A White Paper. EC, COM(2001) 428 final, http: / / eur-lex.europa.eu/LexUriServ/site/en/com/2001/ com2001_0428en01.pdf (accessed 23/03/2011)

${ }^{7}$ Policy-lifecycles (Agenda Setting, Policy formulation, Decision-Making, Policy Implementation, and Policy Evaluation) are e.g. described in [12] and [15]
} 
The recent developments in innovative ICT solutions bear good potentials to implement the concept of Open Government and the principles for Good Governance. In the next sections, we present a concept and approach for such a solution, which focuses on simplifying regulatory impact assessment and which will be implemented in the OCOPOMO project.

\section{Collaborative Scenario Building for Regulatory Impact Assessment}

As already explained above, today's policy-making is challenged by dealing with increasing complexity. The citizens demand the implementation of the Good Governance principles to ensure Open Government. In the course of these developments, regulatory impact assessment (RIA) using foresight exercises such as scenario building received a significant boost in the development of policies and strategies (cf. [3], [7], and [8]).

\subsection{Theoretical Background to Scenario Building for RIA}

Most existing methods and tools for strategic planning and decision-making, which were successful in former more or less stable times such as time series analysis [23] or trend extrapolation [14], do no longer work out in the context of current increasing variety, interconnectivity and alteration as they are barely able to cope with dynamics and complexities. Only a few of them (i.e. Delphis and Scenarios) are robust despite an uncertain long-term future and successful despite a difficult socio-economic environment (cf. [23], p.73). Both, Delphis and scenarios are among a few methods applicable to very complex problem scopes with extra long-term projections into the future, and, hence, are applicable for governance and policy modelling. However, the iterative process of the Delphi technique is slow and very time consuming ([14], p.36). Thus, scenarios have been identified in the course of analysis in OCOPOMO as most suitable to establish an analytical background for policy decisions in the project.

Scenario building can be classified as a method for foresight. It is, therefore, a "systematic, participatory, future intelligence gathering and medium-to-long-term vision building process aimed at present-day decisions and mobilising joint actions" [8]. Scenario building is currently a very popular approach ${ }^{8}$ as it is inherently flexible in terms of design and construction (cf. [7], [8], and [3]). Scenarios help stimulate different internally consistent alternatives of a specific situation and its settings concerning a specific policy issue [5]. With it, scenario building provides the opportunity to gather information and learn about the circumstances of a complex policy issue. Focus of scenarios in foresight exercises is on the identification and description of impact factors as well as on cause and effect interdependencies [23]. Kahn and Weiner explain that scenarios describe hypothetical possible (future) events, which might occur within an environment [13].

Besides, scenario building hardly grounds on literature review. It focuses on stakeholder involvement, instead. Scenarios are often built by groups of experts or stakeholders in workshops [1]. Hence, scenarios support the communication among the

${ }^{8}$ Several technology roadmapping projects funded by the EC (e.g. eGovRTD2020, PHS2020, ROADiBROM) used scenarios for envisioning the future. 
participants thereby bringing down the level of conflict and facilitating cooperation. The participatory process can help build consensus as the different policy alternatives, and the consequences of those alternatives, are shared and discussed by all.

In this context, RIA founded by scenario building can contribute to achieve the Good Governance principles, if it is embedded in a well-designed process, which stimulates reflection and learning among all participants [10]. The next section, therefore, reflects stakeholder involvement through scenario building, which lays the foundation for the open collaboration in policy modelling aimed at in OCOPOMO.

\subsection{Theoretical Background to Stakeholder Involvement for RIA}

The OCOPOMO approach relies on modelling and simulation to express possible strategies and to investigate their potential consequences. Modelling is the process of abstraction that includes the analysis of the policy issue ${ }^{9}$. The model, on which the simulation will run in the end, should rely on evidence-based information. Evidencebased information can be gathered by applying several data collection methods and analyses such as literature review, interviews, workshops and scenarios. Moss states that "eliciting the evidence requires the participation of stakeholders" [18]. Further Richardsen and Andersen [21] stress the importance of group model building, and Kim [14] pointed out the meaning of developing shared mental models. Surveys with stakeholders, such as interviews or group discussions, are traditional approaches to gather the necessary information, which helps modelling how and why individuals and groups react under certain conditions. So, major benefit can be achieved through simulations that help understand the behaviour of complex systems over time. Table 1 gives an overview of popular techniques to gather information thereby outlining its strengths and weaknesses.

Table 1. Strengths and weaknesses of popular techniques for collecting data

\begin{tabular}{|c|c|c|}
\hline Literature review & Interviews & Workshops / group discussions \\
\hline $\begin{array}{l}\rightarrow \quad \begin{array}{l}\text { Very useful to gather } \\
\text { general information }\end{array} \\
\text { on the policy issue } \\
\rightarrow \quad \text { Useful only with } \\
\text { reservations when it } \\
\text { comes to } \\
\text { behavioural } \\
\text { modelling especially } \\
\text { social behaviour } \\
\text { using e.g. statistics } \\
\rightarrow \quad \text { Is not appropriate for } \\
\text { stakeholder } \\
\text { involvement. }\end{array}$ & $\begin{aligned} & \rightarrow \begin{array}{l}\text { Allow spontaneous } \\
\text { adoptions and }\end{array} \\
& \text { intervention through } \\
& \text { the interviewer in } \\
& \text { contrast to written } \\
& \text { surveys [7] } \\
& \rightarrow \quad \text { Necessitates } \\
& \text { transcribing of the } \\
& \text { data received in } \\
& \text { verbal form, which } \\
& \text { can be very time \& } \\
& \text { effort consuming [7] } \\
& \rightarrow \quad \begin{array}{l}\text { Subject to } \\
\text { sentimental biases } \\
\text { and influences }\end{array}\end{aligned}$ & 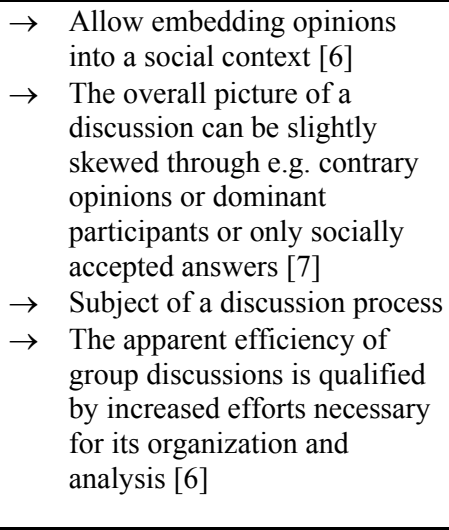 \\
\hline
\end{tabular}

\footnotetext{
${ }^{9}$ See Deliverable 1.2 of CROSSROAD - details in footnote nr. 4.
} 
Interviews and workshops/group discussions can rather exploit their full potential in face-to-face meetings than in online consultations. Group discussions can be better adapted for online consultation than interviews can in particular as there are more advanced tools available that support online group discussion (e.g. discussion forums) than available for online interviewing.

From scenario exercises carried out in several technology roadmapping projects (e.g. eGovRTD2020 and CROSSROAD), we realised that participants feel comfortable with scenario building as it is easy for them to learn how to build scenarios. Scenarios are narratives understood in the language of participating stakeholders [4]. Therefore, people intuitively know how to build scenarios and feel familiar with the method as it allows them to use natural language. Besides, the method promotes the cognitive ability and sagacity of participants, and their ability to act. Scenarios may start from an actual problem, which is perceived as disappointing by a large part of the population and which must urgently be solved. The fact that superior resp. global policy issues (where people normally feel unconscious and powerless) are addressed with the aid of scenarios provides attraction to participants. Additionally there are several (sometimes controversial) scientific and/or political approaches to solve the problem. Breaking down influence factors makes participants see reason that one has the ability to start retail and cause long-term changes [23] although not everything - and also not at once - can be changed. This motivates people in particular to participate in building scenarios. Furthermore, the role of this structure of story-lines is to constrain the discussions and development of scenarios for wider discussion in a constructive manner.

For OCOPOMO the involvement of stakeholders through scenario building is, thus, crucial for a number of reasons:

$\rightarrow$ scenarios are developed in a transparent and inter-subjective manner

$\rightarrow$ scenarios are used as common reference points for policy modelling

$\rightarrow$ all relevant information and data can be included in the scenarios in an unbiased manner

$\rightarrow$ assumptions on developments expressed through the scenarios are shared

$\rightarrow$ although agreement with the views of all relevant stakeholders is not necessary, reading the scenarios developed by others help to understand their viewpoints and therefore supports acceptability

Section 4 outlines the collaborative scenario building approach of OCOPOMO.

\section{Collaborative Scenario Building in OCOPOMO}

In OCOPOMO, we adopt the understanding of Piaget and Senge, who argue a scenario as a textual description (i.e., narrative, structured text) of a perceived view or understanding of a topic under discussion. A scenario may cover an existing world status or mental model of stakeholders (cf. Piaget and Senge cited in [14] on p. 30 and p.32). Alternative scenarios may exist or are developed to describe different aspects and /or alternatives stakeholders have in mind. Different stakeholder groups may develop different sets of scenarios independently (i.e., reflecting e.g. different mental models in scenario sets of different groups). Some of the scenarios may also be 
conflicting among different stakeholder groups. Scenarios may be extended and therewith advance an existing scenario (nesting scenarios). Hence, scenarios as narrative texts enable stakeholders to express their views and concerns on potential policy decisions. For OCOPOMO, scenario building helps to identify conditions and circumstances of the policy under investigation in order to allow better handling of complexity and related uncertainty.

In OCOPOMO two different kinds of scenarios will be developed:

1. Evidence-based stakeholder-generated scenarios

2. Model-generated scenarios

The stakeholder-generated scenarios will subsequently inform simulation models to run alternative policy choices, i.e. to show potential real effects of alternative conditions and courses of action.

The results of the simulation run will generate scenarios to help better understand potential interferences or conflicts of positions of stakeholders, which help them to reflect their positions.

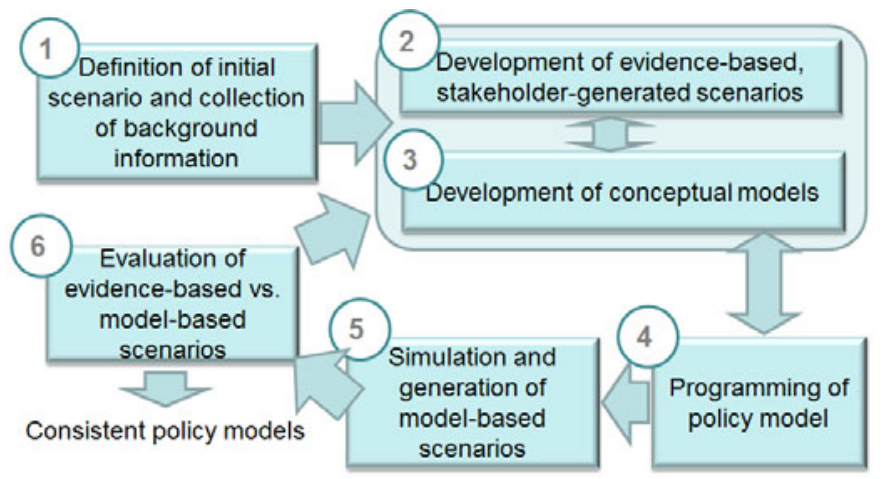

Fig. 1. Sketch of the OCOPOMO overall method including evidence-based user-generated and simulation-generated scenarios

Collaborative scenario building in OCOPOMO will be carried out in phases 1 and 2 (see Fig. 1). While in phase 1, an initial scenario is developed by the policy initiators with respective facilitators to start the discussion, scenarios in phase 2 are developed by stakeholders. Both, face-to-face scenario building workshops and a virtual common workspace for online scenario development are used. The face-to-face scenario building workshops are mainly used in phase 1 and at the beginning of the process in phase 2 to detail the policy issue and the objectives related to the policy issue with initiators of the policy process. The OCOPOMO project encompasses three use cases; hence, the initiators of the policy process are the Campania Region in Italy, the Kosice Self-Governing Region in Slovakia, and the Greater London Authority in UK. Each use case is tackling a specific policy issue (i.e., renewable energy in Kosice Self-governing Region; competence centres for knowledge transfer in Campania Region; and housing facilities in London). Face-to-face scenario building workshops already took place in order to formulate initial scenarios for all three use cases by the 
initiators of the policy process. The initiators (policy owners) were supported by facilitators (i.e. policy analysts, policy consultants from the project team). This step is supported by the use of a common workspace.

As Fig. 1 indicates, the overall policy development of OCOPOMO continues in phase 3 with the development of consistent conceptual models of each policy case, the generation of formal policy models in phase 4 , the simulation of the formal policy models and generation of model-based scenario texts (based on multi-agent simulation), and the evaluation of model-based vs. evidence-based scenarios. OCOPOMO foresees an iterative policy development process, as the simulation results may unveil insights into dependencies, discrepancies and inconsistencies in the narrative scenarios generated by the stakeholders, which have to be resolved in interaction with stakeholders and, hence, may lead to revisions of scenario descriptions in phase 2 until consistency is reached. How the relevant information is extracted from the scenarios and feeds modelling and simulation is shown in an example in section 5. For more details on the overall OCOPOMO policy development process, the reader is referred to [26] and [27].

In OCOPOMO, the initial scenarios of phase 1 will be published at the collaboration space thereby opening the scenario for viewing and manipulating by relevant stakeholders (see Fig. 2). The initial scenarios serve as starting point to involve different stakeholder groups via online means to collaboratively build scenarios. An invitation will be sent to the stakeholders informing them that they can express their views on the policy case via either further elaborating the initial scenario or by generating new (alternative) scenarios. When a scenario will be closed by the facilitator after a while, then affected users will receive information about this action. The same holds true for reopening a scenario after a policy modelling iteration (entering into phase 6). Scenario extensions and updates include the opportunity to rate the scenario and/or parts of it, as well as to discuss on the scenario. Online collaborative scenario building is supported by an adequate scenario generation tool, which shall help producing a narrative that provides the fundamental basis for policy model design.

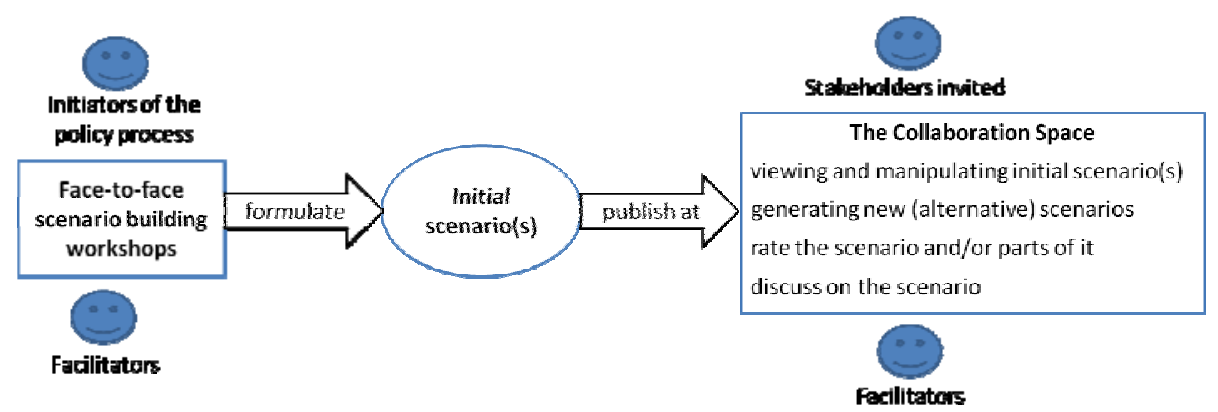

Fig. 2. Simplified depiction of the OCOPOMO evidence-based user-generated scenario building process 
OCOPOMO aims to generate scenarios in order to represent different views of stakeholders in a sensible way, taking into account the goal of the modelling process and its structure, the available information and the computer facilities and available software. Ensuring traceability through the step-wise transformation of narrative scenario texts via the consistent conceptual descriptions (e.g. rule-dependency graphs, actor network diagrams, ontology, etc.) into formal statements (actor and facts descriptions, rule-descriptions) in e.g. java code is an important contribution to achieve open government and to implement the good governance principles (i.e., improving in particular openness, transparency, participation and coherence in policy modelling). In the next section, we exemplify a scenario and the extraction of relevant information for the policy simulation.

\section{Scenario Example from OCOPOMO Use Case}

Stakeholder groups will collaboratively develop scenarios for a strategic area of high interest for the three OCOPOMO use cases. Below, a scenario developed for the Kosice Self-Governing Region use case is presented. The policy to be developed regards investments in renewable energy to reduce dependency on energy import from other countries (especially gas from Ukraine) and reduction of energy consumption of households.

The scenario example reads as follows:

I am living with my wife and two children in a three room flat below the top of the house. The house, in which my flat is in, is not well insulated and, hence, has high consumption of energy for both electricity and heating. Since energy prices are increasing and the energy consumption in my house is very high, I am reflecting alternatives both to decrease consumption such as renovation and to switch the source of energy (if possible). Currently, I am recognising that energy consumption is too high and more and more becomes too expensive for me and my family. Hence, I want to reduce costs of energy consumption. For me who am living in a flat, the association of flat owners is responsible for energy issues, i.e. they have to perform energy audits by law. Citizens need to provide certificates on how efficient energy use is in the house (energy certificates and energy audits). I have to discuss with my family and neighbours. Together we can consult the association of flat owners for a plan to trigger renovation. The association of flat owners, then, calculates the impact of the renovation, the increased energy price and the reduced energy consumption for the future maintenance costs. Urban householders are obliged to create an association; rural houses are not. An association hires service company/building manager (on fee) who is a responsible for dealing with heat and electricity providers. An association may refuse to cooperate with a service company and make arrangements with heat provider on its own. An association itself can be member of a higher association. An association of associations is a board of directors, which e.g. talks with regional or even national governments.

Analysing and structuring the information from the scenario aims at identifying the main aspects relevant for a policy simulation, i.e. stakeholders (i.e. agents), model 
objects, actions, relations and rules. The classes are derived from scenarios using an adopted version of the concept to integrate open collaboration in technology roadmapping developed by the authors, which is introduced in [1]. The subsequent example of analysis presented in Table 2 and Table 3 is by no means exhaustive - it is meant to exemplify the approach in a simple way within the scope of this paper.

From this analysis, conceptual models and formal policy models can be developed. Subsequently, simulation runs produce model-based scenarios, which represent audit trails of the individual rules fired along the simulation. This kind of scenarios is also exposed to the stakeholders in order to a) detect inconsistencies in stakeholder-generated scenarios vs. model-generated scenarios, which lead to revisions of the policy model; and b) understand potential implications of certain policy options, which help to make better informed decisions and reflect stakeholder concerns in decision-making of a policy (see the overall policy development process in Fig. 1).

Table 2. Data derived from scenario including class of agents, class of objects and characteristics

\begin{tabular}{|c|c|c|}
\hline Class of Stakeholders & Class of objects & Characteristics \\
\hline \begin{tabular}{cl}
$\rightarrow$ & \multicolumn{2}{l}{ Households } \\
& $-\quad$ Flat owner \\
& $-\quad$ Flat mates \\
& $-\quad$ Neighbour \\
$\rightarrow$ & Association of flat \\
& owners \\
$\rightarrow$ & Service company \\
$\rightarrow$ & Government \\
- & Regional \\
- & National
\end{tabular} & $\begin{aligned} \rightarrow & \text { House (Flats) } \\
\rightarrow & \text { Heating system } \\
\rightarrow & \text { Energy audits } \\
\rightarrow & \text { Message } \\
& -\quad \text { Demand } \\
& -\quad \text { Provide energy } \\
& \quad \text { certificate } \\
& -\quad \text { Perform energy } \\
& \quad \text { audit }\end{aligned}$ & \begin{tabular}{ll}
$\rightarrow$ & \multicolumn{2}{l}{ House } \\
- & Established in \\
- & Renovated in \\
- & Insulation \\
- & Electricity \\
& consumption \\
- & Heating \\
& consumption
\end{tabular} \\
\hline
\end{tabular}

Table 3. Data derived from scenario including actions, rules and relations

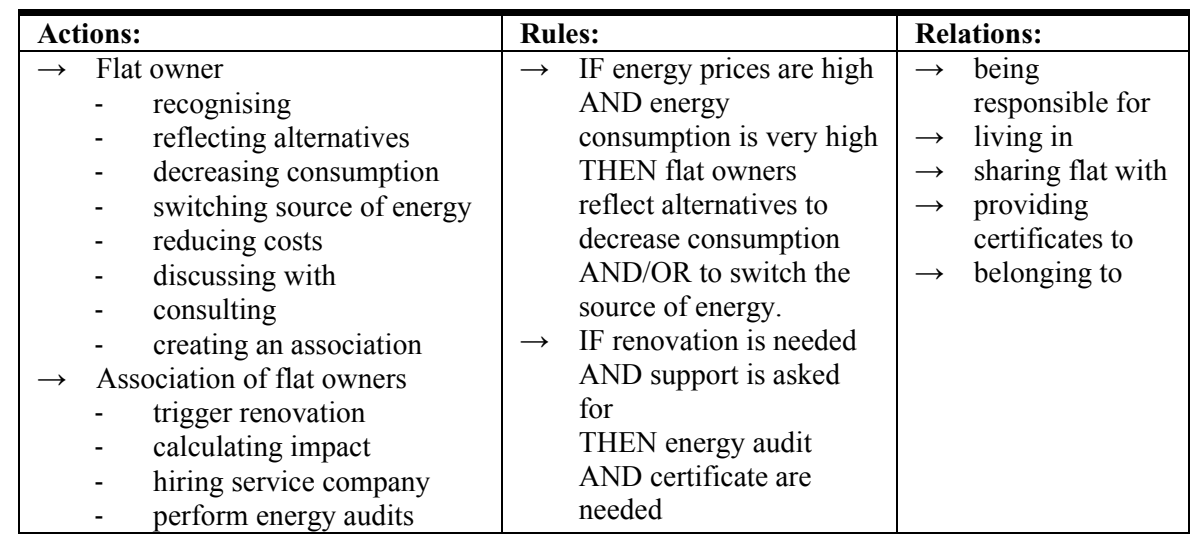




\section{Conclusions and Outlook}

This paper presented an approach to collaborative scenario building, which is applied in OCOPOMO and which supports the realisation of open government and the good governance principles, as it fosters openness, participation, transparency and cohesion. The contribution explained in brief the overall process in which scenario building will be carried out. Involving stakeholders through scenario building in policy development has become a high priority to engage wider stakeholder groups in online and offline consultations (i.e. Open Government). In order to engage stakeholders in the policy modelling process (i.e. regulatory impact assessment through agent-based modelling), we have presented a concept for open collaborative scenario building via online means to evidence-based modelling and simulation. We have investigated different methods to collect data and have assessed them in how far they are useful to be deployed in a comprehensive concept for policy modelling as depicted in Fig. 1.

From a scientific point of view, collaborative scenario building can help validating and evidencing the policy model and simulation results. In this context, the integration of open collaboration among key stakeholders (such as policy analysts, policy operators, wider interest groups of specific policy domains, etc.) ought to be facilitated by using online means. Supporting the participation of external experts and designated stakeholders, as well as the collaboration between the analysts internal to the project helps improving quality of results.

For this purpose, a respective toolbox for collaborative scenario building and policy modelling will be developed in OCOPOMO (see [26] and www.ocopomo.eu). This toolbox aims at helping to understand, model, simulate and validate the next generation of public policy formulation (see Fig. 1).

Besides the toolbox development, the process of transforming scenarios into formal models will be investigated and detailed in order to close the gap between scenarios and the simulation model (i.e. supporting the transformation process and integrating stakeholder-generated scenario development with formal policy modelling using agent-based simulation).

Acknowledgement. OCOPOMO (Open Collaboration for Policy Modelling, FP7ICT-2009-4, http://www.ocopomo.eu/) is a Specific Targeted Research Project (STREP) co-funded by the EC under FP7, topic 7.3 ICT for Governance and policy modelling. The content of this paper is drawn up by the author(s). The EC can by no means be made responsible for any content presented here.

\section{References}

[1] Bicking, M., Wimmer, M.A.: Concept to Integrate Open Collaboration in Technology Roadmapping: Stakeholder Involvement in Strategic E-Government Planning. In: Proceedings of the 44th Annual Hawaii international Conference on System Sciences (44-HICCS). IEEE Press, New York (2011)

[2] Bortz, J., Döring, N.: Forschungsmethoden und Evaluation für Sozialwissenschaftler. Springer, Heidelberg (1995)

[3] Bradfield, R., Wright, G., Burt, G., Cairns, G., Van Der Heijden, K.: The origins and evolution of scenario techniques in long range business planning. Futures 37(8), 795-812 (2005) 
[4] Carroll, J.M.: Scenario-Based Design: Envisioning Work and Technology in System Development. John Wiley \& Sons Inc., Chichester (1995)

[5] Codagnone, C., Wimmer, M.A. (eds.): Roadmapping eGovernment Research: Visions and Measures towards Innovative Governments in 2020. MY Print snc di Guerinoni Marco \& C, Clusone (2007)

[6] Flick, U.: Qualitative Sozialforschung. Eine Einführung. Rowohlt Tb (2002)

[7] Gausemeier, J., Fink, A., Schlake, O.: Szenario-Management: Planen und Führen mit Szenarien. Hanser Publishing, München (1996)

[8] Geschka, H.: Delphi. In Bruckmann, G.: Langfristige Prognosen: Möglichkeiten und Methoden der Langfristprognostik komplexer Systeme. Physica-Verlag, Würzburg (1978)

[9] Geschka, H., Hammer, R.: Die Szenario-Technik in der strategischen Unternehmensplanung. Strategische Unternehmensplanung, Heidelberg, Germany (1997)

[10] Gibson, R.: Rethinking the futures. Nicholas Brealey Publishing, London (1996)

[11] Gustavsson, S., Karlsson, C., Persson, T. (eds.): The Illusion of Accountability in the European Union. Routledge, London (2009)

[12] Howlett, M., Ramesh, M.: Studying Public Policy: Policy cycles and Policy subsystems. Oxford University Press, Oxford (1995)

[13] Kahn, H., Weiner, A.J.: The Year 2000: A Framework for Speculations on the Next Thirty-Three Years. The MacMillan Company Publishing, Basingstoke (1967)

[14] Kim, D.H.: The link between individual and organizational learning. In: Starkey, K., Tempest, S., McKinlay, A. (eds.) How organizations learn: managing the search for knowledge, 2nd edn., Cengage Learning Business Press (2003)

[15] Macintosh, A., Coleman, S.: Promise and Problems of E-Democracy, Challenges of online citizen engagement, Study for the OECD (2004)

[16] Michael, J.: The Politics of Secrecy: Confidential Government and the Public's Right to Know. REVIEWS. Public Administration 61(2), 225-236 (1983)

[17] Möhrle, M., Isenmann, R.: Technologie-Roadmapping - Zukunftsstrategien und Technologieunternehmen. Springer, Heidelberg (2008)

[18] Moss, S.: Policy Modelling: Problems and Prospects. Technical report, CPM Report No. 08-195 (2008), http: / /www. cfpm. org/papers/essamoss . pdf (accessed June $11,2011)$

[19] OECD: Open Government: Fostering Dialogue with Civil Society. OECD Study (2003)

[20] Repnik, H.P., Mohs, R.M.: Good Governance, Democracy and Development Paradigms. Intereconomics 27(1), 28-33 (1992)

[21] Richardson, G.P., Andersen, D.F.: Teamwork in group model building. System Dynamics Review 11(2), 113-137 (1995)

[22] Roberts, A.: Blacked Out. Government Secrecy in the Information Age. Cambridge University Press, Cambridge (2006)

[23] Schelter, B., Winterhalder, M., Timmer, J.: Handbook of Time Series Analysis. Wiley VCH, Chichester (2006)

[24] Smith, S.K., Tayman, J., Swanson, D.A.: Trend Extrapolation Methods. State and Local Population Projections. The Springer Series on Demographic Methods and Population Analysis, pp. 161-183 (2002)

[25] Sträter, D.: Szenarien als Instrument der Vorausschau in der räumlichen Planung. Regionalprognosen. Methoden und ihre Anwendung. Akademie für Raumforschung und Landesplanung: Forschungs- und Sitzungsberichte \# 175, Hannover, pp. 417- 440 (1988)

[26] Wimmer, M.A.: Open Government in Policy Development: From Collaborative Scenario Texts to Formal Policy Models. In: Natarajan, R., Ojo, A. (eds.) ICDCIT 2011. LNCS, vol. 6536, pp. 76-91. Springer, Heidelberg (2011)

[27] Wimmer, M.A., Bicking, M.: Collaborative Scenario Building For Policy Modelling. In: Ghoneim, A., Veerakkody, V., Kamal, M. (eds.) tGov2011 Workshop Proceedings, Digital Proceedings. Brunel University, West London (2011) 